\title{
Study on the Blend of SBS and Polystryrene and Properties of Their
}

\author{
Mixture \\ Jun Zhou ${ }^{1, a^{*}}$, Xi-Hua Du ${ }^{1, b}$, Wei Yue ${ }^{1, c}$ \\ ${ }^{1}$ School of Chemical Engineering and Technology, Xuzhou Institute of Technology, Xuzhou, Jiangsu, \\ China \\ aemail: zhoujunxz@126.com, bemail: dxh@xzit.edu.cn, cemail: 644810298@qq.com
}

Keywords: polystyrene; styrene-butadiene-styrene; blending modification; mechanical property Abstract: Aiming at the defects of polystyrene (PS), PS is modified by blending with thermoplastic elastomer styrene-butadiene-styrene (SBS). The blends of SBS/PS as the object of study, this paper studies the mechanical properties of SBS/PS blends with different proportions and the effect of the content of SBS on the properties of SBS/PS blends. In the course of the experiment, SBS/PS blends with different proportions were prepared by melt blending method. Then the mechanical properties of the blends were tested. Through the test and data analysis, the result is that impact strength and extension rate at break are improved when SBS is blended in PS, but bending strength comes down as well as tensile strength. The comprehensive properties of SBS/PS blend are the best when the mass ratio of PS and SBS is 20: 80 .

\section{Introduction}

Polystyrene (PS) has many advantages, such as good transparency, easy processing, and low cost, etc. But PS also has some disadvantages, such as low thermal deformation temperature and the impact strength of PS is relatively poor ${ }^{[1]}$.

The composite material is a new material, which is formed by two or more than two kinds of material or artificial synthesis. The two main types of materials can be classified into functional composite materials and structural composite materials. Composite materials commonly used have a variety of fiber, metal wire and inorganic rigid particles, etc. Blending modification can improve the physical and mechanical properties, transparency, coloring, antistatic property, and can reduce the production cost ${ }^{[2]}$.

In this paper, a thermoplastic elastomer SBS was modified to improve the mechanical properties of PS. We tried to get a best blended proportion of SBS and PS through investigation on the impact strength, the tensile strength, the yield strength and the elongation at break of the SBS/PS composite materials with different ratios.

\section{Experimental section}

$1 \mathrm{Kg}$ of blended materials of SBS/PS were accurately weighed and the ratio of mass fraction of SBS is $0 \%, 20 \%, 40 \%, 60 \%, 80 \%$ and $100 \%$, respectively. Table 1 lists the material used in the experiment and their specifications. The blended particles were processed in the injection molding machine and five of impact and tensile splines of each group which meet the standard of GT/T 1043.1-2008 were prepared. Tensile and impact tests were carried out with the electronic universal mechanical testing machine and impact test machine with a simply supported beam. 
Table 1 Materials and their specifications

\begin{tabular}{cc}
\hline Materials & Specifications \\
\hline PP & HIE-1 \\
SBS & YH-791 \\
\hline
\end{tabular}

\section{Results and discussion}

Through the blending modification experiment, we found that the different proportion of SBS has great influence on the mechanical properties of the blends. Table 2 exhibits the total data of the effect of SBS content on the mechanical properties of SBS/PS composites materials.

Table 2 The total data of the effect of SBS content on the mechanical properties

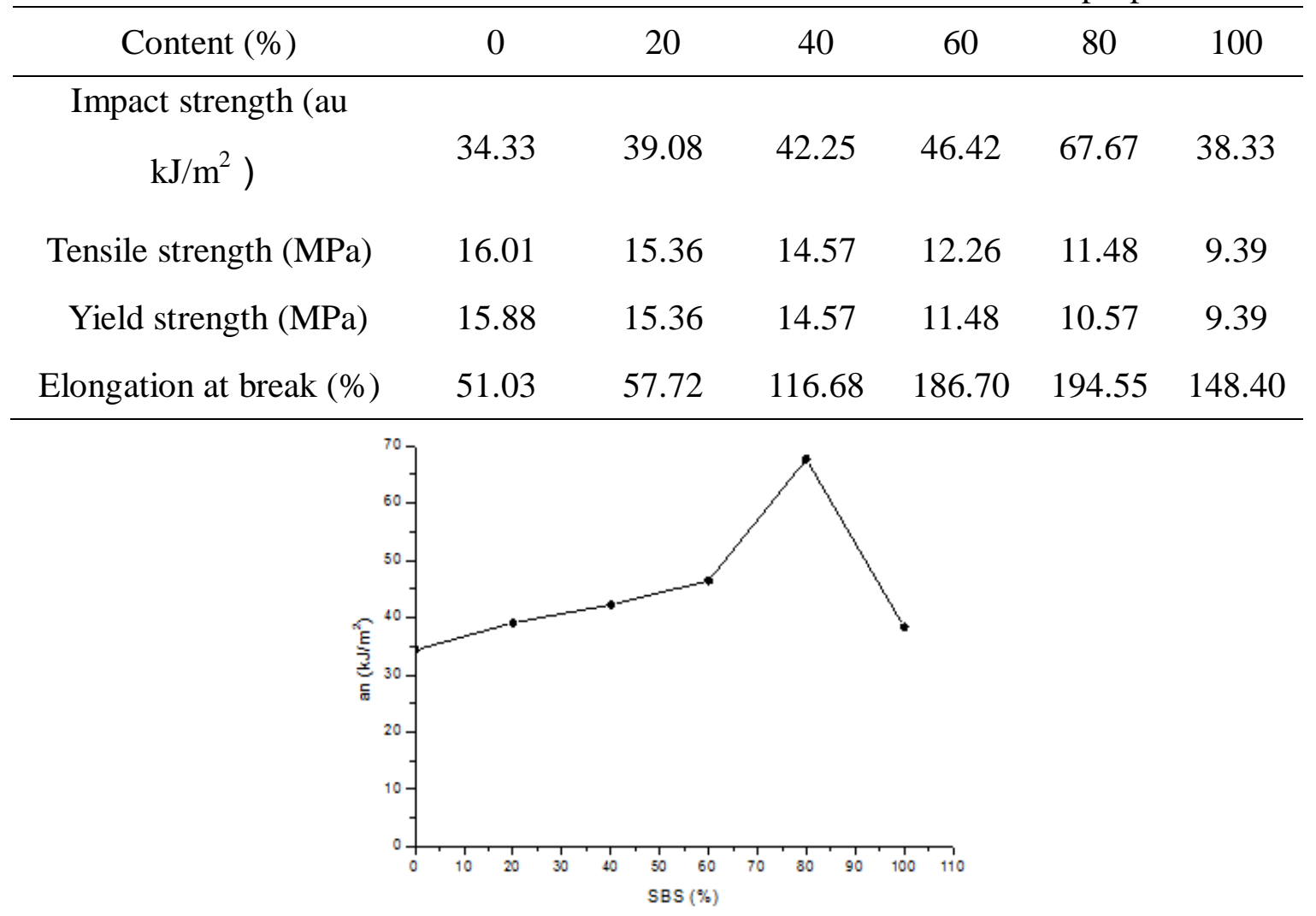

Figure 1 Effect of the content of SBS on the notched impact strength of SBS/PS composites

Seeing from figure 1, when the content of SBS gradually increased from 0 to $60 \%$, the notched impact strength of the blends increased from $34.33 \mathrm{~kJ} / \mathrm{m}^{2}$ to $46.42 \mathrm{~kJ} / \mathrm{m}^{2}$ and the change trend is relatively slow. When the content of SBS increases to $80 \%$, the notched impact strength of the blends increases to $67.67 \mathrm{~kJ} / \mathrm{m}^{2}$. But when the content of SBS is increased to $100 \%$, the notched impact strength of the blends is suddenly reduced to $38.33 \mathrm{~kJ} / \mathrm{m}^{2}$. Thus it can be seen that when the content of SBS is $80 \%$, the notched impact strength of the blends is better. 


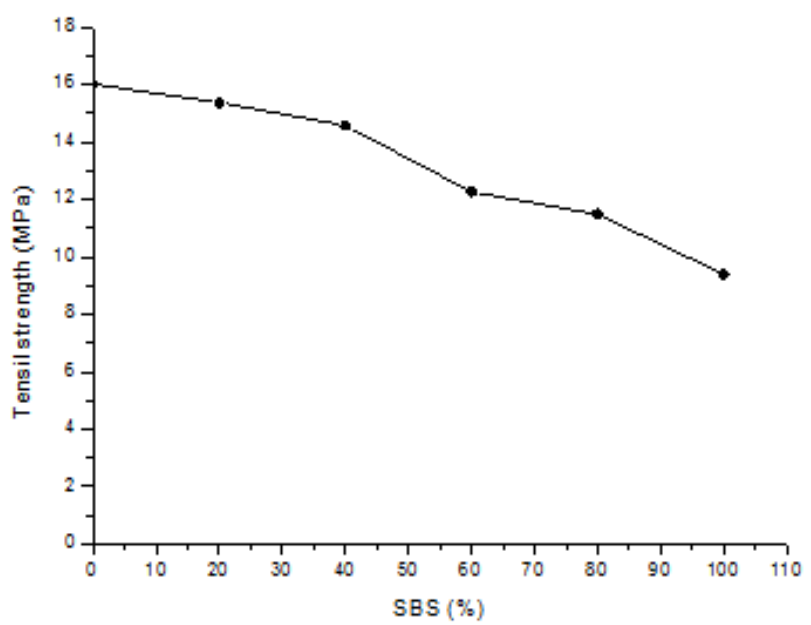

Figure 2 Effect of the content of SBS on the tensile strength of SBS/PS composites

From figure 2 it can be seen that the tensile strength of SBS/PS blends decreased gradually with the increase of content of SBS. The reason may be due to thermoplastic elastomer SBS has high toughness and elasticity, and rigid are lower than PS. So the resistance to tensile stress is relatively weak.

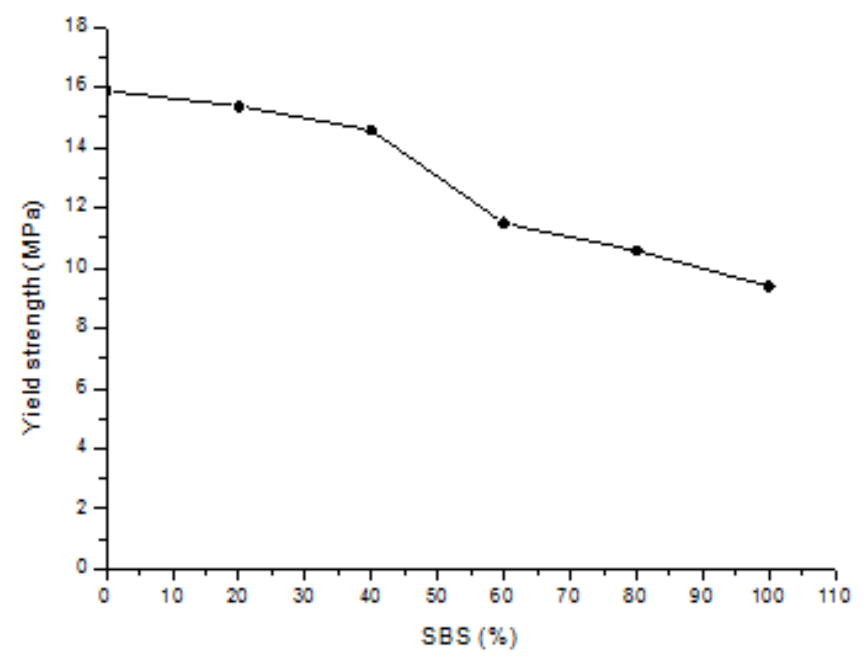

Figure 3 Effect of the content of SBS on the yield strength of SBS/PS composites

We may discover from figure 3 that the yield strength of SBS/PS blends decreased from $15.88 \mathrm{MPa}$ to $9.39 \mathrm{MPa}$ with the increase of the content of SBS which is similar to variation the trend of the tensile strength. But it can be seen from the figure that the decline is relatively slow when the content of SBS is less than $40 \%$ or greater than $60 \%$. 


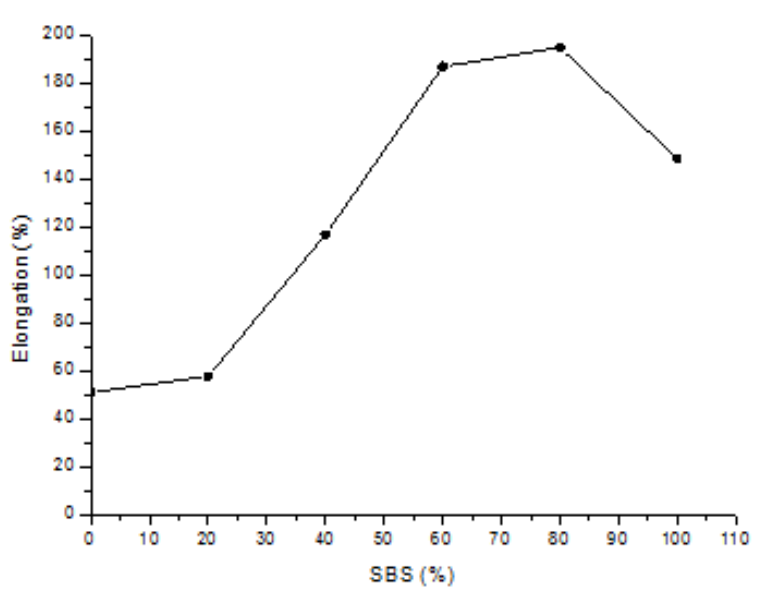

Figure 4 Effect of the content of SBS on the elongation at break of SBS/PS composites

From Figure 4 we can find that the characteristics of change trend of notched impact strength and elongation at break of SBS/PS blends is similar. When the content of SBS is less than $80 \%$, the elongation at break of the blends increased gradually from $51.03 \%$ to $194.55 \%$ but when the content of SBS is higher than $80 \%$, the elongation of the blends decreased to $148.4 \%$. So when the content of SBS is $80 \%$, the elongation at break of SBS/PS composites is the maximum.

\section{Conclusions}

When the content of SBS was less than $80 \%$, the notched impact strength and elongation at break of SBS/PS blends increased significantly with the increase of SBS content. But the tensile strength and yield strength of the blends will be decreased in different degrees. In SBS/PS blends, when the content of SBS was $80 \%$, the blends have the best comprehensive properties with the notched impact strength $67.67 \mathrm{~kJ} / \mathrm{m} 2$, the tensile strength $11.48 \mathrm{MPa}$, the yield strength $11.48 \mathrm{MPa}$, the elongation at break $194.55 \%$. The modification of SBS/PS blend system provides a reference for improving the performance of PS and SBS, and has a positive significance for the application field of PS.

\section{Acknowledgements}

The authors are grateful for financial support from General Program on University Science Research of Jiangsu Province (Grant No. 15KJB480003) and Research Project of Xuzhou Institute of Technology (Grant No. XKY2014311).

\section{References}

[1] Genlin Wang, Zhengping Fang, Chengwei Xu. Progress in PVC/PS blendings[J]. China plastics, 1998, 12(6): 19-24. (In Chinese)

[2] Aixin Yang, Shenyan Cui. Hubei chemical industry, 2000, 17(1): 31-32. (In Chinese) 